\title{
Pinch Analysis of a Partly Integrated Pulp and Paper Mill
}

\author{
Elin Svensson ${ }^{1}$, Simon Harvey ${ }^{1, *}$ \\ ${ }^{1}$ Dept. of Energy and Environment, Chalmers University of Technology, Göteborg, Sweden \\ *Corresponding author. Tel: +46 31772 8531, Fax: +4631821 928, E-mail: simon.harvey@chalmers.se
}

\begin{abstract}
The pulp and paper industry, with its wood biomass feedstock, has promising opportunities to become a key player in the biorefinery arena. A successful implementation of biorefinery pathways requires optimization of the energy system through process integration, and can lead to both increased and diversified revenues as well as a r eduction of global $\mathrm{CO}_{2}$ emissions. This paper presents the results from a pinch analysis of a partly integrated Kraft pulp and paper mill. The objective was to identify the potential for energy efficiency improvements, focusing on possibilities to save steam. Another objective was to identify practical retrofit solutions for the mill heat exchanger network and to estimate the costs for the required investments. The potential for energy savings at the mill is estimated at $18.5 \mathrm{MW}$, i.e. $12 \%$ of the current steam demand. Two alternative retrofit options are presented in the paper. A straightforward retrofit that is easy to implement enables $5.8 \mathrm{MW}$ of steam to be saved at a cost of $€ 0.13$ million per MW of saved steam. A second more extensive retrofit option is also presented which could achieve steam savings of $11 \mathrm{MW}$ at a cost of $€ 0.14$ million per MW of saved steam. Assuming that the steam savings lead to a reduced use of bark fuel in the power boiler, the payback period of both energy saving retrofit investments is estimated to be less than about 16 months.
\end{abstract}

Keywords: Pinch analysis, Pulp and paper industry, Retrofit, Steam savings.

\section{Introduction}

Extensive research aiming at improving energy efficiency and heat integration of pulp and paper plants has been conducted during the past decades. The pulping industry, with its wood biomass feedstock, has clear opportunities to become a key player in the biorefinery arena. Successful implementation of biorefinery concepts requires maximized heat integration, and can lead to increased and diversified revenues as well as reduced global $\mathrm{CO}_{2}$ emissions.

There are many possible biomass conversion paths in biorefineries, including thermochemical, biochemical, mechanical and chemical processes. Thermo-chemical conversion usually involves gasification, pyrolysis or direct combustion, with significant excess heat flows at different temperature levels. Pinch analysis is an essential tool for investigating opportunities for heat integration both within the thermo-chemical biorefinery plant, and between the thermo-chemical biorefinery plant and other nearby industrial process plants with significant heat flows, such as a Kraft pulp mill.

Integration of biorefinery operations within a pulp and paper plant is a typical application of heat cascading, whereby heat for one plant is supplied by excess heat from another. Opportunities for biorefinery-related heat-cascading in the pulping industry have been widely discussed in the literature. A review report published in 2008 [1] discusses general issues for process-integrated biorefineries and also discusses the following specific examples:

Drying of biomass (e.g. forest residues, bark)

Pelletizing in connection with drying and forest residues leaching

Energy combine with ethanol production

Energy combines with other industries

A chemical market pulp mill with optimized energy consumption could achieve a surplus of energy which can be utilized to produce electricity, enable decreased firing of bark fuel in the mill's power boiler which can be dried and sold on the biomass fuel market, or enable 
integration of appropriate biomass energy combine process concepts. An integrated chemical pulp and paper mill, on the other hand, needs to import energy, since the paper machine is a large consumer of heating steam. However, energy savings within an integrated mill also lead to economical savings and decreased environmental impact since they provide a way to reduce the fuel import demand. The mill studied here is a partly integrated pulp and paper mill which means that part of the produced pulp is sold as market pulp and the rest is used to produce paper. One objective of this study was therefore to contribute to the knowledge base about the energy situation in such a partly integrated pulp and paper mill. It is important to note that very few published studies in the literature address energy efficiency at partly integrated pulp and paper mills based on the Kraft process. Therefore, it is important to contribute to further development of the knowledge about the energy situation in this type of mill. The main objective of this work was to identify potential energy savings through pinch analysis at a partly integrated pulp and paper mill. The aim was also to suggest practical retrofit solutions for how to achieve a reduced energy demand, or alternatively, how to release excess heat at higher temperatures. The costs of the proposed measures were also estimated.

The results presented in this paper are based on the results of an MSc thesis project conducted by two students at Chalmers University of Technology in close co-operation with mill personnel at the Billerud Karlsborg mill. The thesis report by Eriksson and Hermansson, Pinch analysis of Billerud Karlsborg, a partly integrated pulp and paper mill [2] provides a detailed description of the work and results of the energy systems analysis.

The pinch study was part of a larger project conducted in co-operation between research groups at several Swedish universities ${ }^{1}$, the Swerea MEFOS Research Institute and the pulp and paper mill Billerud Karlsborg. The aim of the project, hereafter called the Billerud project, was to establish a f ramework for process integration studies with a regional perspective in the pulp and paper industry. One of the objectives of the project was to improve co-operation between different institutions and actors who use and develop process integration tools such as pinch technology and reMIND (see for example reference [9]). The results of the pinch analysis presented in this paper are therefore planned to be used in connection with other models developed within the project. The opportunities for this model interaction are discussed in Section 5.2.

\section{Methodology}

This study was conducted using pinch technology, and it is assumed that the reader is familiar with the basic concepts. For a comprehensive description of the theory, the reader is referred to references [3] and [4]. The principal steps of the methodology are described below [5]:

Define the process stream system to be investigated with respect to opportunities for improved energy efficiency.

Extract stream data and establish energy saving targets using pinch analysis.

Analyze the existing heat exchanger network in order to identify pinch rule violations.

Make changes to the existing network so as to solve some of the pinch violations.

Evaluate the profitability of the proposed changes to the heat exchanger network.

Process data representing typical average winter operation was retained for the study. Most of the data required was available directly in the plant's process data-log, but some additional

\footnotetext{
${ }^{1}$ Energy Engineering at Luleå University of Technology, Business Administration and Social Sciences at Luleå University of Technology, Energy Systems at Linköping University, School of Natural Sciences, Linnæus University and Heat and Power Technology, Chalmers University of Technology.
} 
measurements were needed. Manufacturer specifications, engineer estimations, and mass and energy balances were also used to complete the data set required. Stream-specific minimum temperature differences for heat exchanging and heat transfer coefficients were used in accordance with previous studies [5].

The costs of the proposed heat exchanger network retrofits were calculated based on area requirements, with surface area costs taken from recent pinch studies of similar mills [6]. The cost of piping was estimated at $50 \%$ of the installed heat exchanger cost based on typical cost estimation factors presented in [4], since the distances between streams were not investigated. Additional costs for e.g. instrumentation, control and pumping costs were also neglected.

\section{Mill description}

The studied mill is a partly integrated Kraft pulp and paper mill situated in northern Sweden, producing 300000 tonnes/year of pulp and paper (40\% pulp and 60\% paper). Electricity is cogenerated in a back-pressure steam turbine unit. The mill was built over 80 years ago, but the main parts still in use were built in the early 1980's. Continuous energy improvements have been made during the lifetime of the plant. However, given the availability of new research results and the continuous changes of energy market conditions, it is of interest to reinvestigate the potential for process integration and energy savings on a regular basis. Pinch analysis provides a good tool for this type of investigation and has now been used at the Billerud Karlsborg mill for the first time.

\section{Results}

\subsection{Theoretic potential for energy savings}

A large number of heat exchangers supplying heating or cooling to mill process streams were identified (27 cold and 35 hot streams). Adopting stream-specific values of $1 / 2 \Delta \mathrm{T}_{\min }$ for different stream types, ranging from $0.5 \mathrm{~K}$ for utility steam to $8 \mathrm{~K}$ for air, the process pinch temperature is $148^{\circ} \mathrm{C}$. This means that the mill has a net deficit of heat above $148^{\circ} \mathrm{C}$ and a net surplus below. The theoretical minimum external heating requirement is $135.4 \mathrm{MW}$.

The composite curves for the mill are shown in Fig. 1. The potential internal heat exchange is illustrated by the overlap of the hot and cold curves. In a theoretical case with maximum heat exchange between the curves, the hot streams should be able to provide all heat to the process except for the actual steam demand. Achieving this for a retrofit design would, however, require far too many new heat exchangers to be profitable.

In the grand composite curve (Fig. 2), the composite curves are merged. The horizontal line below the pinch represents the surface condensers, which provide about $41 \mathrm{MW}$ of heat at $60^{\circ} \mathrm{C}$. This heat is currently used for warm water production from raw water. This heat could be released by making use of the hot streams in the heat pocket below the surface condensers' temperature. These streams are hot effluents from the evaporation and bleaching plant and outgoing air from the pulp dryer and the paper machine. There is also a heat pocket at around $70^{\circ} \mathrm{C}$ which could enable heat integration for several streams in this region. 
Composite Curves

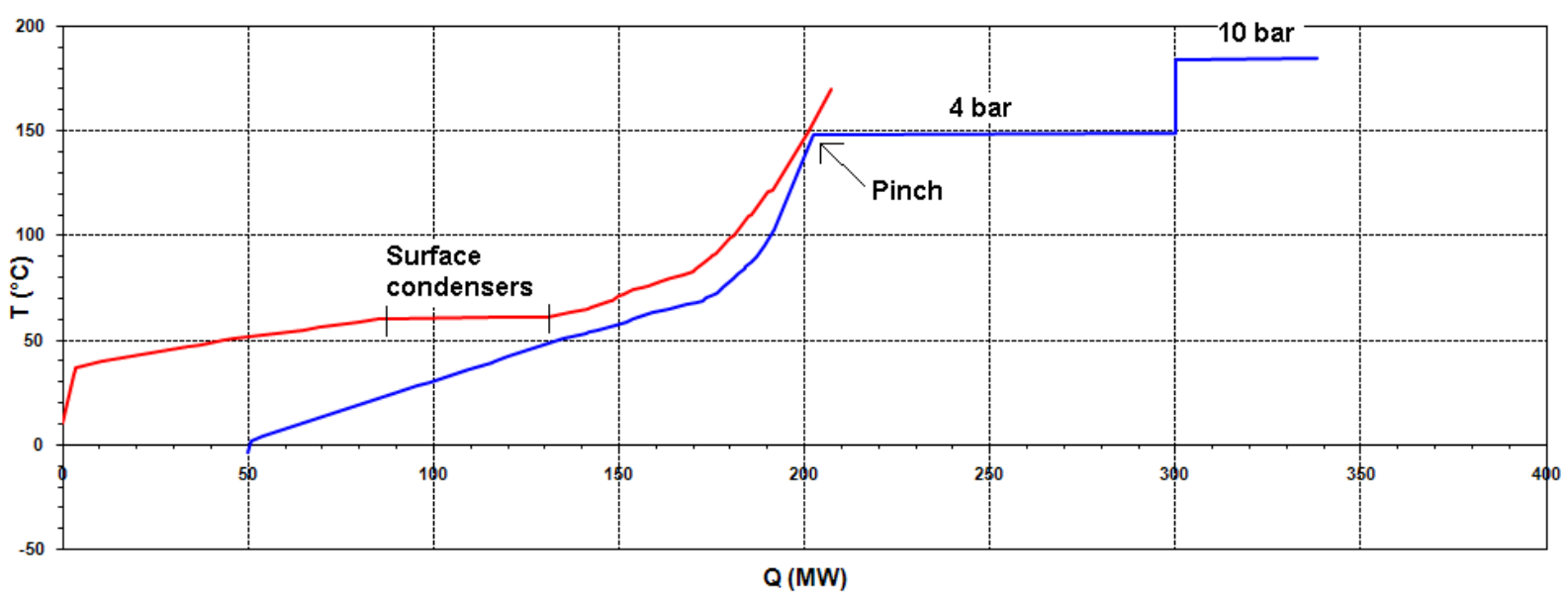

Fig. 1. Composite curves for the process.

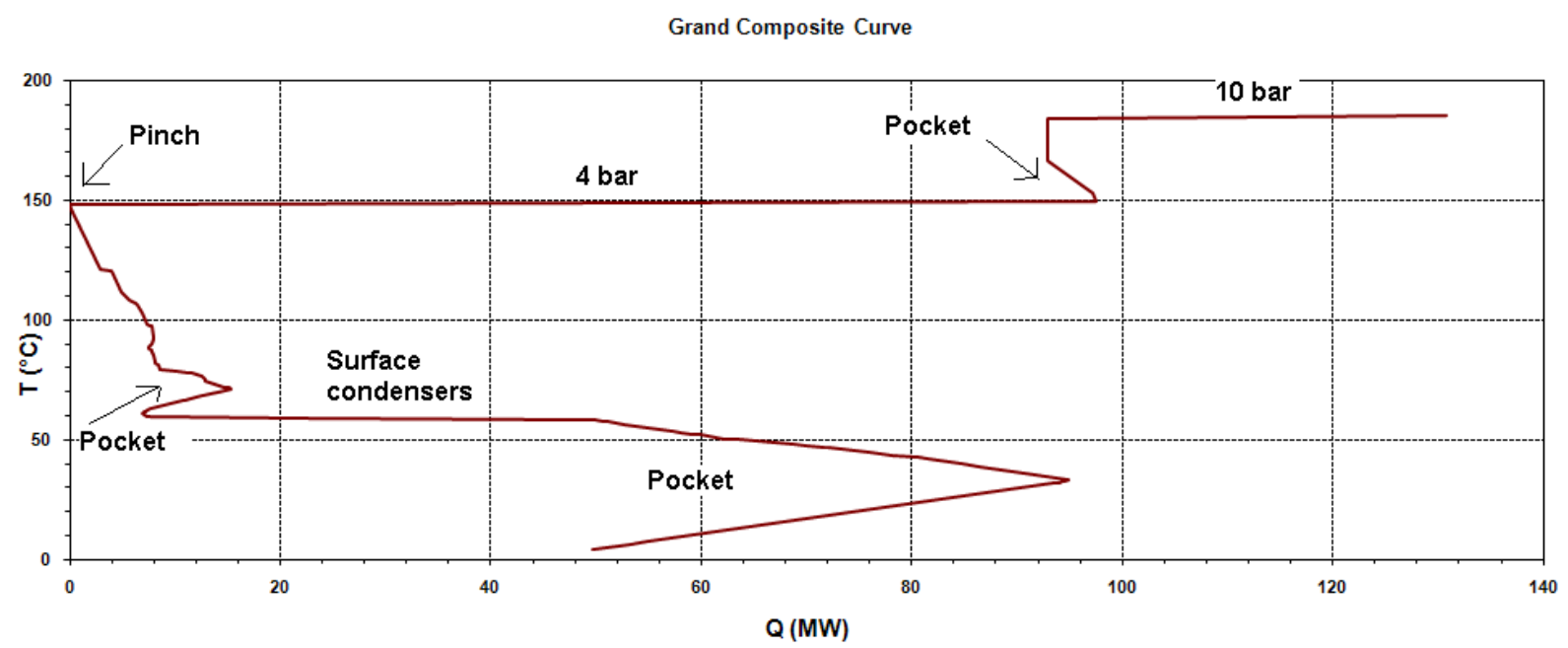

Fig. 2. Grand composite curve for the process.

\subsection{Pinch violations}

The difference between the actual steam demand and the minimum demand for hot utility is due to pinch violations i.e. non-optimal heat exchange. With a minimum hot utility of 135.4 MW and a current steam demand of 153.9 MW, the resulting pinch violations for the plant are 18.5 MW. This corresponds to a theoretical steam-saving potential of $12 \%$ of the current steam demand. All violations are due to heating below the pinch.

\subsection{Retrofit suggestions}

In this section, two retrofit options are presented: Retrofit I involves relatively straightforward changes whereas Retrofit II is more extensive. The focus of both retrofit options is on eliminating steam users below the pinch temperature. This could be achieved by improved heat recovery from high temperature water effluent streams in drains or by heat exchanging streams differently in the network. The major difference between the proposals is that in Retrofit I only changes that do not affect the hot and warm water system (HWWS) are considered, whereas in Retrofit II this process section is included. 


\subsubsection{Retrofit I}

In Retrofit I, the main focus has been to save as much steam as possible without interfering with the HWWS. This retrofit could achieve steam savings of $5.8 \mathrm{MW}$ of low-pressure (LP) steam, which corresponds to $4 \%$ of the present steam demand and $32 \%$ of the pinch violations. In Table 1, the cold streams are presented together with the hot stream that, according to the proposal, should replace the LP steam that is currently used. The resulting steam savings are also indicated. In this proposal, steam is replaced by condensate streams and hot effluents from the evaporation plant. Costs for new heat exchangers include costs for new heat exchanger area and piping. The total cost for the Retrofit I proposal is estimated at $€ 759000$ and the resulting specific cost is $€ 130000$ per MW.

Table 1. Steam savings resulting from retrofit measures in Retrofit I.

\begin{tabular}{lll}
\hline Cold stream & New hot stream & Steam saved (MW) \\
\hline E2 filtrate & Condensate from stripper & 1.0 \\
E2 filtrate & Condensate from stripper & 1.3 \\
White water for pulp dryer and paper & & \\
machine & B-condensate & 2.1 \\
White water for paper machine & Condensate cooling pulp dryer & 1.5 \\
\hline Total & & $\mathbf{5 . 8}$ \\
\hline
\end{tabular}

\subsubsection{Retrofit II}

The more extensive heat exchanger network retrofit results in larger energy savings than Retrofit I. In addition to the steam savings of Retrofit I, changes that affect the HWWS are also included in Retrofit II. The replaced steam users are shown in Table 2. In total it is possible to save approx. twice as much steam as in Retrofit I, i.e. about $11 \mathrm{MW}$ of LP steam. This corresponds to $7 \%$ of the present steam demand and $60 \%$ of the pinch violations. The total cost of the Retrofit II proposal is estimated at $€ 1580000$, or $€ 143000$ per MW.

Table 2. Steam savings resulting from retrofit measures in Retrofit II.

\begin{tabular}{lll}
\hline Cold stream & New hot stream & $\begin{array}{l}\text { Steam } \\
\text { (MW) }\end{array}$ \\
\hline E1 filtrate & Liquor cooling & 1.6 \\
E2 filtrate & Condensate from stripper & 1.0 \\
E2 filtrate & Condensate from stripper & 1.3 \\
D0 filtrate & Hot water & 2.6 \\
White water for pulp dryer and & paper & \\
machine & & B-condensate \\
Local heating & Digester liquor & 2.1 \\
White water for paper machine & Condensate cooling pulp dryer & 1.0 \\
\hline Total & & $\mathbf{1 1 . 0}$ \\
\hline
\end{tabular}

In addition to the changes made in Retrofit I, it is necessary to modify or build seven additional heat exchangers. When replacing a heat exchanger in the HWWS it is important that the new network still can achieve the same temperatures in the hot and warm water tanks.

\subsection{Other findings from the pinch study}

\subsubsection{The paper machine}

There is a lack of information regarding how the heat recovery in the paper machine is currently implemented. A thorough investigation of the heat recovery system would most 
probably identify further opportunities for improvement. Using a system similar to the one used in the pulp dryer, with a fluid transferring heat from the outgoing air to the incoming air, could improve efficiency and provide operational flexibility with respect to outdoor temperature. At present, there are large amounts of energy released to the surrounding with the outgoing air effluent stream due to its high humidity content.

\subsubsection{Bleaching plant}

The bleaching plant is the largest user of hot water in the mill. A comparison with other mills indicates that there is a potential for energy savings at the studied mill and that there are reasons to investigate the bleaching plant more thoroughly. Using presses instead of filters when washing the pulp and keeping the temperature at a $\mathrm{m}$ ore even level between the bleaching steps are two ways of lowering the demand for steam and hot water and thus improving the energy efficiency.

\subsubsection{Hot and Warm Water System (HWWS)}

It would be possible to reach a higher temperature in the hot water tank with some changes in the heat exchanger network. This would lead to lowered steam demand in the subsequent hot water users. This option was not included in the study, since traditional pinch analysis is not the best approach to such tank temperature optimization. It would, however, be interesting to further analyze this opportunity.

\subsection{Economic evaluation}

There are several ways for the mill to benefit from potential energy savings. The most obvious and straightforward is to simply reduce the amounts of oil and bark fired in the power boiler. Due to large seasonal variations it is, however, not possible to reduce the boiler load during all parts of the year, since during summer, it already runs at minimum load. Other options include investing in a condensing turbine, delivering district heating or integrating a biorefinery process.

To make an initial assessment of the profitability of the proposed energy-efficiency measures, a simple calculation was performed for the option of bark savings. Assuming bark savings can be achieved during two thirds of the year, the economic savings will be $€ 107000$ per MW and year and hence the payback period will be less than $16 \mathrm{~m}$ onths for both proposals. Considering that the fuel reduction is likely to be oil rather than bark during parts of the year, the payback period could well be even lower.

\section{Discussion}

\subsection{Seasonal variations}

The study was carried out for winter operating data. The summer steam demand is lower because of increased ambient temperatures. Therefore this study is not representative for the whole year.

No detailed investigation of possible economic benefits through, for example, reduced burning of bark or district heating delivery were made. To analyze these options, more information regarding yearly variations in bark boiler firing, steam system and demand of heating and cooling in general are required. The effect of these seasonal variations on the steam-saving potential could, however, be estimated using the results of previous studies [6]. The effect on the overall energy balance of the mill could, for example, be studied using the 
reMIND tool, thereby connecting the results from this pinch analysis to other studies within the Billerud project.

\subsection{Pinch-reMIND interaction}

It is possible to use the results of the pinch analysis presented in this paper in an energy system model developed using the reMIND simulation and optimization tool (see e.g. [7]). This model interaction is based on what has previously been shown to be a good way to use the results from pinch analysis in optimization studies using reMIND, see for example [8] and [9]. For a more general discussion of the role of optimization for efficient implementation of process integration measures in industry, see [10].

In reMIND, optimization is carried out by using mixed integer linear programming in order to minimize the system cost. The system cost includes amongst others, the investment costs of different measures that can be taken to change the system. The structure of the energy system is represented as a n etwork of nodes and branches where branches represent energy or material flows. One node may represent, for example, a process line or a single equipment unit. It may also represent a possible steam-saving investment which will be the case when representing the results from the pinch analysis. Multi-period optimization can be modelled in reMIND which makes it possible to consider seasonal variations in the overall energy system studied.

The two retrofit alternatives identified in the pinch analysis could, for example, be modelled as two different investment options in the reMIND model, each resulting in a certain steam saving2 which can be achieved for a specified investment cost.

\section{Conclusions}

The theoretical potential for energy savings at the studied mill was estimated at $18.5 \mathrm{MW}$, corresponding to $12 \%$ of the current steam demand. Two retrofit proposals to accomplish parts of this theoretical potential were suggested. Assuming that the steam savings lead to a reduced use of bark in the power boiler, the pay-back period of the energy savings investment is estimated to be less than about 16 months.

\section{Acknowledgements}

The excellent work of Lina Eriksson and Simon Hermansson who conducted the pinch study during their MSc thesis work is gratefully acknowledged. We would also like to thank Monika Resin, process engineer at Billerud Karlsborg, who co-supervised their work and of course also the rest of the staff at the mill who contributed to the study. Professor Thore Berntsson (examiner of the MSc thesis and supervisor to the first author of this paper) is also acknowledged for his contributions to this work.

This research project was led by the Energy Engineering group at Luleå University of Technology with funding provided by the Swedish Energy Agency, Billerud Karlsborg AB and Billerud Skog.

\section{References}

[1] T. Berntsson. Swedish Pulp Mill Biorefineries - A vision of future possibilities. Swedish Energy Agency, report nr ER 2008:26, ISSN 1403-1892, 2008.

\footnotetext{
${ }^{2}$ The steam saving measure could, for example, be modelled as a fictitious steam production unit, i.e. as one option to partly cover the steam demand at the mill.
} 
[2] L. Eriksson, S. Hermansson. Pinch analysis of Billerud Karlsborg, a partly integrated pulp and paper mill. Master's thesis, Heat and Power Technology, Energy and Environment, Chalmers University of Technology, Göteborg, 2010.

[3] I.C. Kemp. Pinch Analysis and Process Integration: A User Guide on Process Integration for the Efficient Use of Energy, Butterworth-Heinemann, Oxford, UK, 2007.

[4] R. Smith. Chemical Process Design, McGraw-Hill, Inc, New York, 1995.

[5] E. Axelsson, M. Olsson, T. Berntsson. Heat integration opportunities in average Scandinavian kraft pulp mills: Pinch analyses of model mills. Nordic Pulp and Paper Research Journal. 21 (2006) 466-475.

[6] J. Persson, T. Berntsson. Influence of seasonal variations on energy-saving opportunities in a pulp mill. Energy. 34 (2009) 1705-1714.

[7] M. Karlsson, P. Sandberg. The MIND method: a decision support system based on MILP. Paper 8 in Sandberg, P., 2004. Optimisation and Co-operative Perspectives on Industrial Energy Systems. PhD Thesis, Division of Energy Systems, Department of Mechanical Engineering, Linköping University, Sweden. 2004.

[8] I.-L. Svensson, J. Jönsson, T. Berntsson, B. Moshfegh. Excess heat from kraft pulp mills: Trade-offs between internal and external use in the case of Sweden - Part 1: Methodology. Energy Policy. 36 (2008) 4178-4185.

[9] C. Bengtsson, M. Karlsson, T. Berntsson, M. Söderström. Co-ordination of pinch technology and the MIND method--applied to a Swedish board mill. Applied Thermal Engineering. 22 (2002) 133-144.

[10]J. Klemes, F. Friedler, I. Bulatov, P. Varbanov. Sustainability in the process industry Integration and optimization. McGraw-Hill, New York, 2010. 